Materiales de Construcción

Vol. 67, Issue 326, April-June 2017, e120

ISSN-L: 0465-2746

http://dx.doi.org/10.3989/mc.2017.08215

\title{
Impact of the use of alternative fuels on clinker reactivity
}

\author{
K. Serrano-González $\bowtie$, A. Reyes-Valdez, O. Chowaniec \\ Division of Engineering and Technology, Universidad de Monterrey, (Monterrey, Mexico) \\ \karla.serrano@udem.edu
}

Received 18 September 2015

Accepted 20 September 2016

Available on line 22 March 2017

\begin{abstract}
The use of alternative fuels in the cement industry has increased its relevance in the past decades due to their ecological and economic benefits. In concert with the efforts to increase its use, several studies have focused on their potential impact with respect to clinker reactivity and how they could affect the expected physical and mechanical properties. This work studied the effects of five alternative fuels on the reactivity of eight industrial clinker samples, considering several analytical techniques. Differences were identified among the clinker samples after replacing the alternative fuels, mainly with simultaneous eliminations, as in samples S4, $\mathrm{S} 5$ and $\mathrm{S} 8$. The modifications were related to the polymorph, size and reactivity of tricalcium silicate and to the clinker profile during the hydration process, due to the $\mathrm{SO}_{3}$ consumption rate. These changes were expressed in the higher compressive strengths in comparison with the original reference clinker.
\end{abstract}

KEYWORDS: Portland cement; Clinker; Alternative fuels; Hydration; Emissions

Citation/Citar como: Serrano-González, K.; Reyes-Valdez, A.; Chowaniec, O. (2017) Impact of the use of alternative fuels on clinker reactivity. Mater. Construcc. 67 [326], e120. http://dx.doi.org/10.3989/mc.2017.08215.

RESUMEN: Impacto del uso de combustibles alternativos sobre la reactividad del clínker. El uso de combustibles alternativos en la industria cementera ha ido en incremento en las últimas décadas debido a su beneficio ecológico y económico. En línea con los esfuerzos enfocados en incrementar su uso, se han realizado distintos estudios enfocados en determinar su impacto potencial en la reactividad del clínker y en cómo pueden afectar sus propiedades físicas y mecánicas. Este trabajo estudia el efecto de cinco combustibles alternos sobre la reactividad de ocho muestras industriales de clínker, considerando diferentes técnicas analíticas. Se identificaron diferencias principalmente cuando se realizaron eliminaciones simultáneas de varios combustibles, como en las muestras S4, S5 y S8. Las modificaciones se basan en un cambio en el polimorfo, tamaño y reactividad del silicato tricálcico y del perfil de hidratación de los clínkeres, relacionado con el ritmo del consumo del $\mathrm{SO}_{3}$. Las modificaciones se reflejaron en un incremento en la resistencia a la compresión.

PALABRAS CLAVE: Cemento Portland; Clinker; combustibles alternativos; Hidratación; Emisiones

ORCID ID: K. Serrano-González (http://orcid.org/0000-0002-8668-2158); A. Reyes-Valdez (http://orcid. org/0000-0003-2952-0870); O. Chowaniec (http://orcid.org/0000-0001-7658-6552)

Copyright: (C) 2017 CSIC. This is an open-access article distributed under the terms of the Creative Commons Attribution License (CC BY) Spain 3.0.

\section{INTRODUCTION}

Cement production is a highly energy demanding process that emits large quantities of greenhouses gases (GHG) into the atmosphere. In 2010, the carbon dioxide worldwide emissions from cement production were $1.352 \mathrm{GtCO}_{2}$ from a total of 13.14 $\mathrm{GtCO}_{2}$ of the industrial $\mathrm{CO}_{2}$ emissions (which are $30 \%$ of total global GHG emissions) (1). According to the global initiatives in favor of environmental care, the cement industry has a special interest in reducing GHG emissions. 
The use of alternative fuels has increased over the past decades. The relevance of these fuels as an eco-effective and responsible solution is represented by providing waste disposal for other industries and processes and thus being able to capture the energetic capacity of wastes as a substitute for fossil fuels that have an intense environmental impact.

However, even when the use of alternative fuels reduces the harmful environmental effects of the cement production process, this use also presents a potential impact on clinker reactivity, which could affect the physical and mechanical properties of clinkers.

The fossil fuel that is often used in Mexico due to its availability and cost is pet coke. In addition several wastes as potential alternative fuels have been identified, such as whole tires and tire chips, soil with hydrocarbons from petrochemical exploration and exploitation (referred to here as mass), carbon residues, oils and urban waste, designated as refuse-derived fuel (RDF). As a drawback, these materials are the wastes of other industries and have a heterogeneous composition as well as a variable calorific content. To avoid a negative impact on the final cement formulation, the physical behavior and production cost of the cement, it is important to verify that the use of these alternative fuels in the production of clinker does not cause significant alterations to its reactivity.

The scope of this work is to determine the changes that occur in the reactivity of industrial clinker samples with the use of alternative fuels. This investigation was performed through chemical, mineralogical, microscopic, calorimetric and physical evaluations to contribute to the understanding of the changes in clinker reactivity, by itself, and with the incorporation of clinker into cement and ready-mix admixtures.

\section{ALTERNATIVE FUELS IN CEMENT INDUSTRY}

Cement production involves the extraction and transformation of raw materials (mainly consisting of limestone, clay and iron ore) into clinker as a product of the sintering process at $1450{ }^{\circ} \mathrm{C}$ and grinding with gypsum as well as additions into cement powder that are commercially available in bags or bulk for the construction of different structures for social and economic development of communities and countries.

The alternative fuels considered in this study were incorporated at the precalciner, with the exception of carbon residue that was ground and added with pet coke in the precalciner and also in the main burner.

\subsection{Benefits of the use of alternative fuels in cement industry}

The use of alternative fuels in rotary kilns helps to reduce the $\mathrm{CO}_{2}$ emissions of the process by the replacement of fossil fuels preserving non-renewable resources. Additionally, this use represents a safe alternative to dispose of wastes that, in other conditions, could be disposed of in landfills or in waste incinerators, as stated by the Cembureau, European Cement Association (2). This use portrays a multidisciplinary approach to global concerns about the future of the national and international communities (3).

Using tires, rubber, paper waste, waste oils, sewage sludge, plastics and spent solvents as alternative fuels in the cement industry maximizes the energy recovered from these materials, presents a guarantee of their safe disposal, produces an overall benefit considering the releases to air, water and land and prevents the depletion of non-renewable resources.

\subsection{Effect of alternative fuels in the quality of the product}

An inefficient control of alternative fuels could lead to an increase in the energy consumption of the kiln by operational changes that would be needed to assure a low level of free lime and this control could cause a series of adverse effects in clinker reactivity. When the kiln is operated with excessive heat, volatiles would be released generating more possibilities of build-ups in the cooler parts of the kiln, usually in the preheater. The clinker obtained under these conditions has a lower porosity, with large alite crystals $\left(\mathrm{C}_{3} \mathrm{~S}\right)$ that contribute to a dusty clinker rather than a nodular and more reactive clinker due to the inefficient cooling process. Additionally, this process could cause increases in the water demand and in the energy consumption during the grinding process due to the larger size of the crystals (4-6).

A change in the proportions of the main phases of the clinker and its crystalline structure would impact reactivity and solubility of clinker, and with it the rate of consumption of calcium sulfate, its balance in the system and thus its interaction as cement with chemical admixtures. As stated by Tuthill, when the aluminate reaction is accelerated the consumption of sulfates increases and the silicate hydration is affected in cements with lignin based admixtures to the point that a significant retardation effect is registered (7). Depending in the level of tricalcium aluminate $\left(\mathrm{C}_{3} \mathrm{~A}\right)$ in the clinkers this could affect the sulfate balance during the reaction with the chemical admixtures (8). Low $\mathrm{C}_{3} \mathrm{~A}$ clinkers are marginally under sulfated with or without admixtures. The optimum $\mathrm{SO}_{3}$ should be determined with and without the use of the admixtures to achieve the maximum performance in the field.

\section{EXPERIMENTAL}

\subsection{Materials and preparation of samples}

This investigation was focused on industrial scale clinker production to evaluate different operational factors and conditions that could modify industrial 
clinker formation and reactivity rather than laboratory-produced clinkers. Alternative fuel selection for each plant, in Mexico or any other country, depends on the available sources of generation and the disposition of industrial wastes near each facility, and the public or private infrastructure and organization that promotes waste collection must be able to compile and classify all of these residues and make them available to several industrial sectors, as in this case cement producers.

A combination with five alternative fuels (biomass, mass, carbon residue, tires and RDF-refuse derived fuel) led to seven modified clinker samples in addition to the reference: S1-with all the alternative fuels, S2-without Biomass, S3-without RDF, S4-without Biomass-Tires-Mass, S5-without Biomass-Mass-RDF, S6-without Biomass-Tires, S7-without Carbon Residue and S8-without Mass.

\subsection{Analytical techniques}

An $80 \mathrm{~kg}$ sample of clinker was collected directly from the output of the cooler of an industrial rotary kiln with each combination of alternative fuels. The clinkers were prepared by isolating the fraction between $3 / 8$ " and mesh 10 , for the complete analysis. The characterization of the clinker includes chemical analysis, morphology, mineralogy, mechanical evaluation and isothermal calorimetry. The clinker analyses and treatments were guided by the Quality Manual from CEMEX, based on national and international standards (9-11).

Clinkers were analyzed using the following equipment: X-ray fluorescence spectroscopy, Philips Model PW 2400/00 for chemical analysis, X-ray diffraction powder spectroscopy, Philips PW 3040/00 for mineralogical analysis, optical microscopy, Leica Model DMRXA2 for microstructural analysis, and an isothermal calorimeter, TAM Air Thermostat for the determination of the hydration profile.

The cement hydration profile was determined by isothermal calorimetry over a 24 hour period, for the samples without admixtures, and over a 60 hour period, for the cement or ready-mix admixtures. The compressive strength of mortar cubes was determined at 1, 3, 7 and 28 days with constant w/c ratio (0.485), as specified for ordinary Portland cements in ASTM-C-109 and NMX-C-414-ONNCCE, the American and Mexican cement standards.

\section{ANALYSIS AND DISCUSSION OF RESULTS}

\subsection{Chemical and Mineralogical Analysis}

Chemical composition, control modules and Bogue potential phases of the eight samples are presented in Table 1. These results show that the clinkers were chemically equivalent. Further comparisons were focused on their mineralogy and microstructure. This study was centered on the changes of the clinker crystals, their phase formation and the impacts on the clinker reactivity as determined by isothermal calorimetry.

The mineralogical information of the samples, shown in the Table 2, indicates that the general distribution between silicates and aluminates remained within the same range among all of the different clinker samples. However, considering the specific crystalline structure of the stabilized silicates, some differences were identified. Three alite structures were identified in the samples: de la Torre, Nishi and Mumme. Although all of these are monoclinical, with different lengths in their crystalline structure and two of three angles of $90^{\circ}$, their differences correspond to the size of the crystal unit cell. The de la Torre volume is the largest (4325.214 $\left.\AA^{3}\right)$, the Nishi is second $\left(1128.031 \AA^{3}\right)$ and finally, Mumme $\left(720.174 \AA^{3}\right)$. A higher reactivity of this phase is expected in the smaller crystalline structure of Mumme. The crystalline system of these phases in combination with the size of the alite grains determines the phase reactivity during the hydration process. In $\mathrm{S} 2$, in which biomass was eliminated, the alite remained without any change, as in the reference. In S3 or S8, in which RDF or mass was removed, some alite changed from de la Torre to Nishi or Mumme, decreasing the size of the alite and increasing its reactivity. The largest changes were registered in S7, in which the carbon residue was replaced, and the removal of 2 or 3 alternative fuels, as in S4, S5 and S6, in which the presence of Mumme alite was identified in combination with the other alite structures, decreasing the overall balance for the volume of alite. Changes in the proportion of aluminates were also identified, from $5 \%$ of $\mathrm{C}_{3} \mathrm{~A}$ in the reference to $3.8 \%$ and $4.1 \%$ in $\mathrm{S} 6$ and $\mathrm{S} 8$, respectively.

To obtain a more detailed mineralogical phase description, a silicate extraction of each clinker type was performed. These results indicated that ferroaluminate $\left(\mathrm{C}_{4} \mathrm{AF}\right)$ increased from $5.9 \%$ in $\mathrm{S} 1$ to $7.9 \%$ in $\mathrm{S} 8$. The $\mathrm{C}_{4} \mathrm{AF}$ content also increased in S4, S5, S6, S7 and S8 (samples that also presented a change in the crystalline formation of the alite). Both changes are expected to affect the hydration process (in its early and later ages), their sulfate demand and, as a consequence, their interaction with chemical admixtures.

\subsection{Microstructural Analysis}

Microscopy is an analytical technique that complements other procedures to determine the size, form and distribution of the crystals, information related with the thermal profile and physical conditions at which the raw materials were exposed during the complete production process (since dehydration in the preheater tower, sinterization in the 


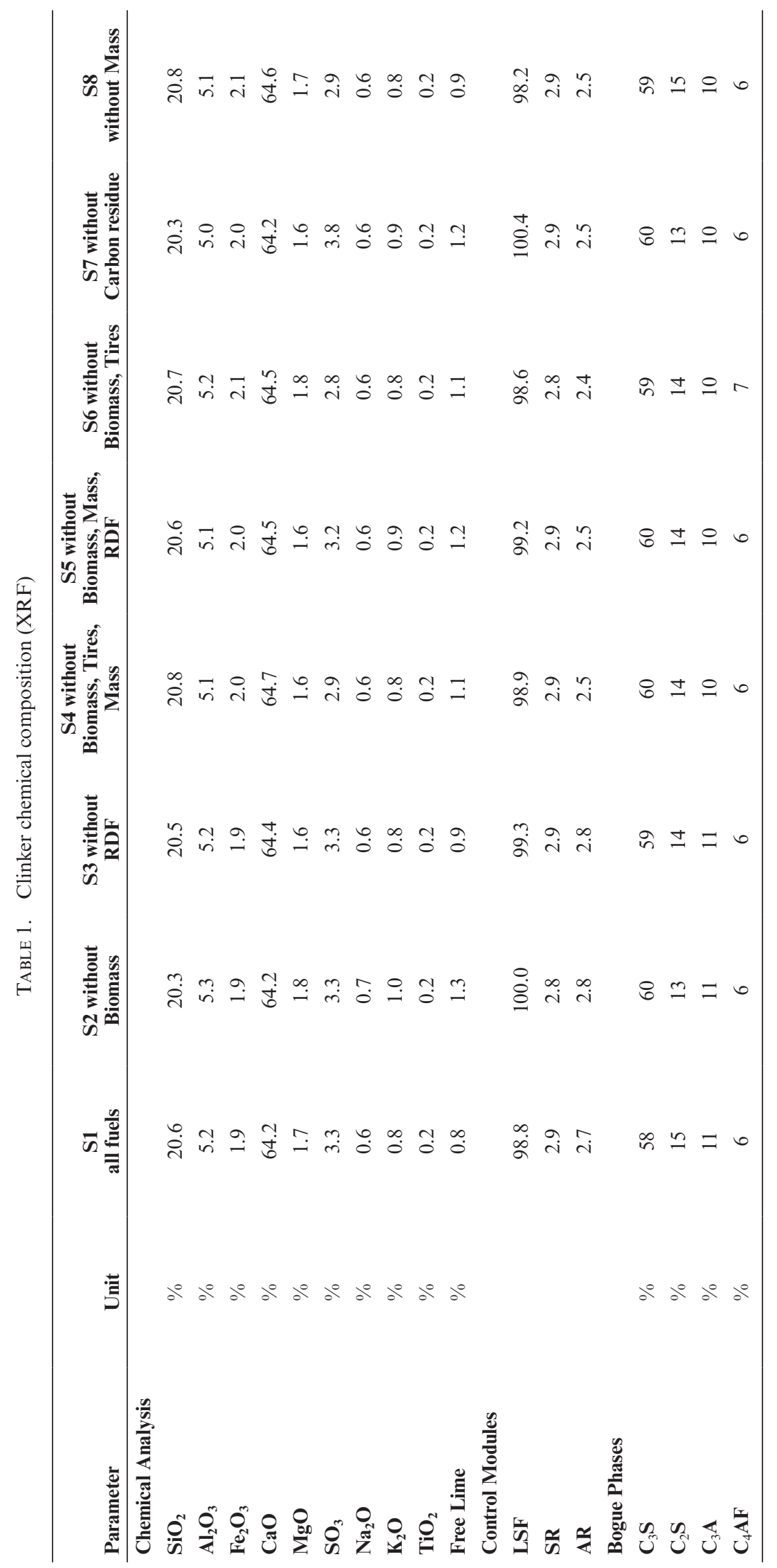




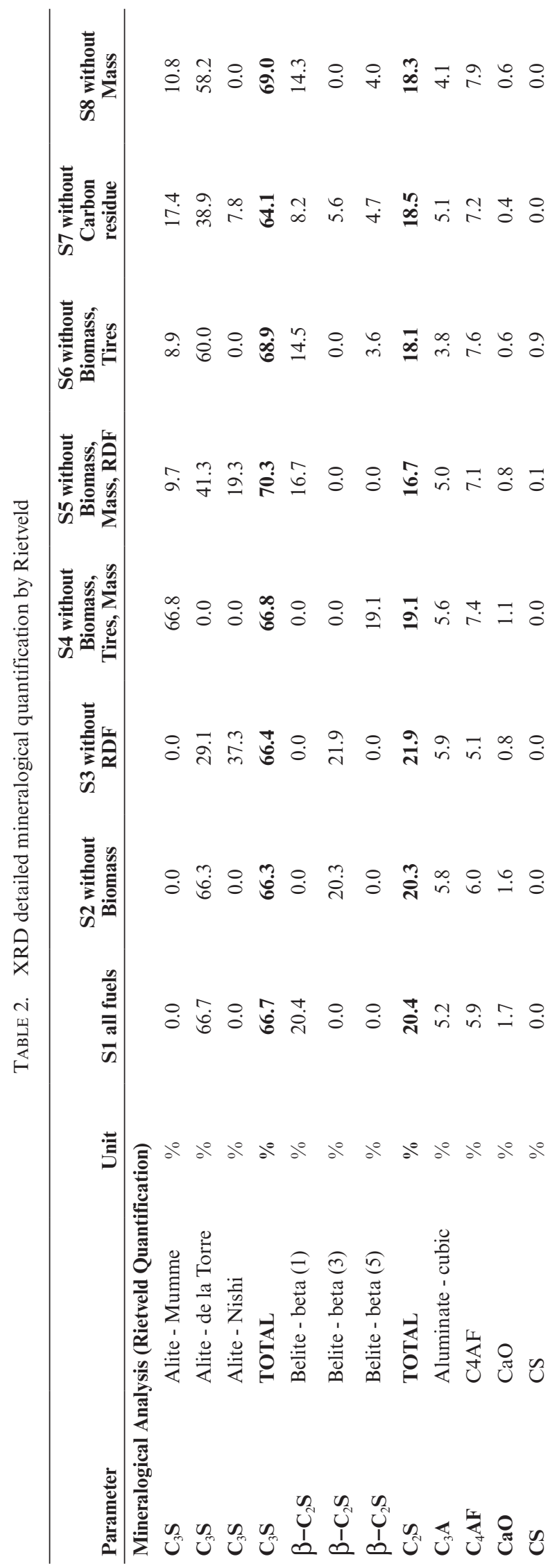

rotary kiln and cooling phase in the final production stage).

The analysis obtained with optical microscopy indicates some changes in the clinkers produced when alternative fuels were removed from the rotary kiln. Results showed changes in clinker reactivity considering general standard parameters that includes size and morphology of the crystals, as shown in Table 3.

The size of the $\mathrm{C}_{3} \mathrm{~S}$-alite is expected to be between 18 to $23 \mu \mathrm{m}$ to consider that its reactivity is in its highest level and the heating rate during the process was adequate. When the size of $\mathrm{C}_{3} \mathrm{~S}$ increases its reactivity decreases because it takes more time for it to interact with other species due to the higher superficial area and steric hindrance. There was no significant change in the size of alite grains along the eight samples. Regarding the morphology, in the literature there are recognized three polymorphs for alite: idiomorphic (high level of calcination), pseudomorphic (regular calcination) and xenomorphic (low calcination). As shown in Table 3 , in the reference, S1, was identified $25 \%$ of idiomorphic alite and $75 \%$ of pseudomorphic, ratio that was improved in almost all the samples, except in S2. All the modifications of the fuels used in the rotary kiln improved the formation and stabilization of the alite increasing idiomorphic formation, with an expected benefit in the physical performance of the cements. In particular S4, S5 and S6 reached 75\% of idiomorphic alite and $25 \%$ of pseudomorphic alite. The relation between these samples is that two (S6) or three (S4, S5) alternative fuels were removed from the formula, so the greatest impact in the alite formation was identified for those clinkers indicating that the maximum temperature of the sintering process was raised with the replacement of those alternative fuels.

The optimum size for belite crystals is between $25-40 \mu \mathrm{m}$, in this case, opposite to the alite, an increase in the size of the crystal represents an improved reactivity because it is related to the sintering time, where higher belite represents a longer sintering time and better crystal formation. In this parameter, as for the alite, all the clinker samples with the variation of the used fuels were equivalent to the reference in its belite crystals size, with a moderate short sintering time. Complementarily, the morphology of belite is related to the effectiveness of the cooling process, where $\alpha$-belite is the most reactive phase, then $\alpha^{\prime}$ and finally $\beta$-belite with the least reactivity. In the reference clinker (S1), S3, S4, S5 and S6 was identified a 75\% of $\alpha^{\prime}$-belite and $25 \%$ of $\beta$-belite, and only in $\mathrm{S} 2$ that relation was even worsened as it moved to $50 \%: 50 \%$ $\left(\alpha^{\prime}: \beta\right)$. With S7 and S8 was registered an improvement in the stability of $\alpha^{\prime}$-belite mainly by a better cooling process, being $100 \%$ of belite in those samples. The translation of the quantified parameters in the microscopic analysis to the operational conditions in the 


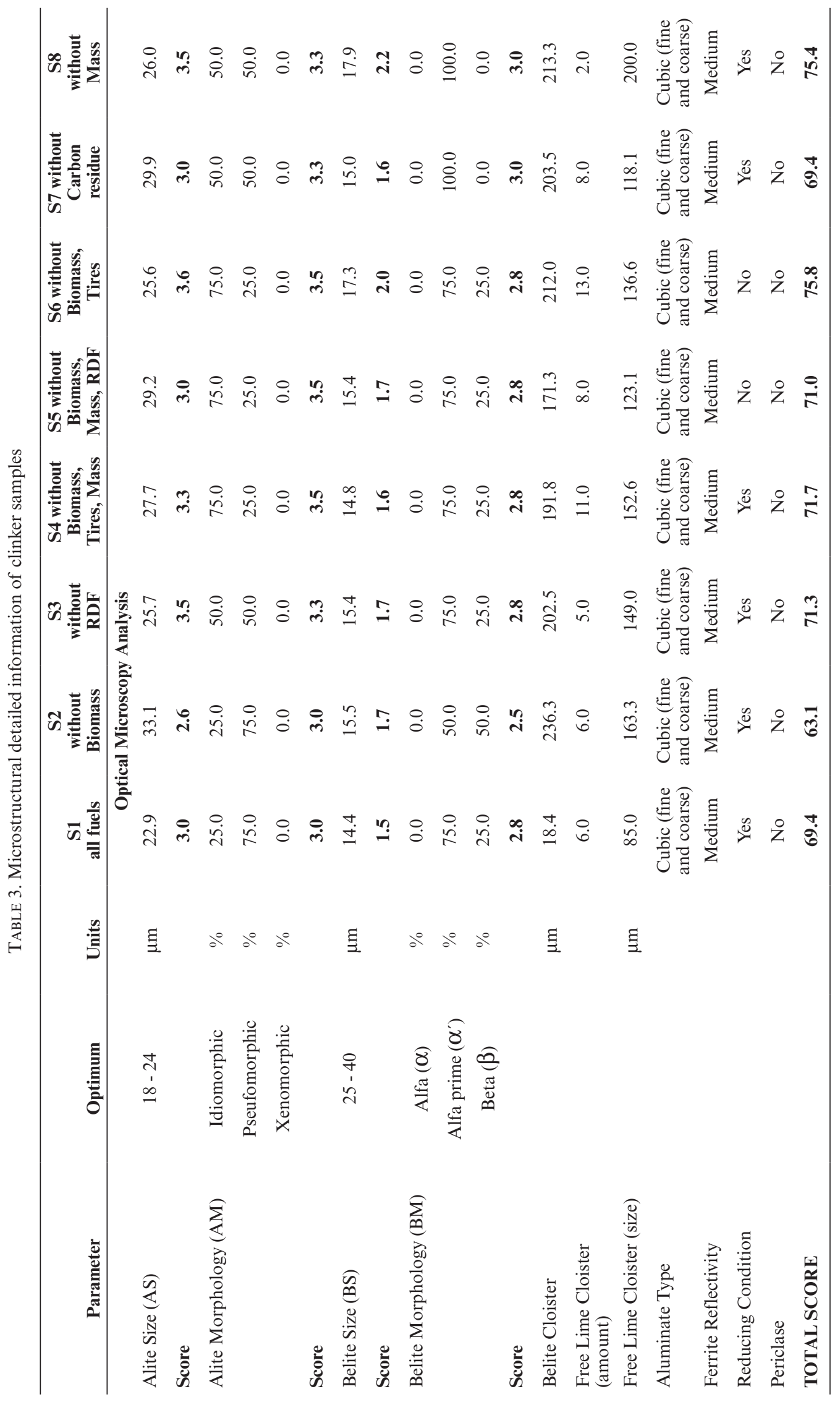


rotary kiln is based mainly in the size and form of the two silicate phases (alite and belite). The results of the eight samples are reported in Table 4. The main difference with the elimination of some of the alternative fuels was in the formation of the alite, whose morphology was improved with S3, S4, S5, S6, S7 and S8. With the replacement of one, two or three alternative fuels the maximum temperature for the sintering process was increased, favoring the reactivity of the clinker.

\subsection{Isothermal Calorimetry}

Chemical, mineralogical and microstructural configuration of the clinkers leads to changes in the physical performance of the cements, for that purpose, and prior to the compressive strength determination, isothermal calorimetry analysis was performed using different $\mathrm{SO}_{3}$ contents in a range of $4-5 \%$ of $\mathrm{SO}_{3}$ to identify the behavior of each clinker within those sulfate values.

Three specific ages were followed in the calorimetric analysis: 6, 18 and 24 hours. At 6 hours the liberated heat is related to the immediate interaction between clinker and calcium sulfate dihydrate (gypsum) in the early stage of the hydration, it was expected that the initial liberated heat decrease with the addition of gypsum as it performs its retardation effect, this behavior was identified in S3, S4, S5 and S7 and a different reaction, with almost no change was registered for S2, S6 and S8 as presented in Figure 1. A change in the initial hydration profile of those cements could impact its relation with the chemical admixtures that interact with the cement since the initial stage of its hydration and is guided by the available ions in solution. At 18 and 24 hours the trend of the liberated heat of all the cement samples except S7 was always increasing with the $\mathrm{SO}_{3}$ content, as expected, where gypsum addition allows the hydration reaction to proceed at a more complete form (12). It is usual to detect that the $\mathrm{SO}_{3}$ level that performs the best at early age may differ from the optimum in later ages, even though what governs the optimum $\mathrm{SO}_{3}$ in the industry is the 24 hours results, which determines the initial interaction between sulfates and the clinker phases and the setting time and workability properties that the final mortar or concrete mass would have, conventionally without the use of ready-mix admixtures (13). Due to the differences identified in the performance of the clinkers in isothermal calorimetric analysis with different sulfate contents two $\mathrm{SO}_{3}$ levels were used for the calorimetric evaluation with admixtures and for compressive strength testing to identify specific interactions as synergies or incompatibilities with chemical admixtures.

In Figure 1 are marked in circles the optimum $\mathrm{SO}_{3}$ values considering the maximum generated heat: (a) $4.25 \%$ as it was identified for the reference

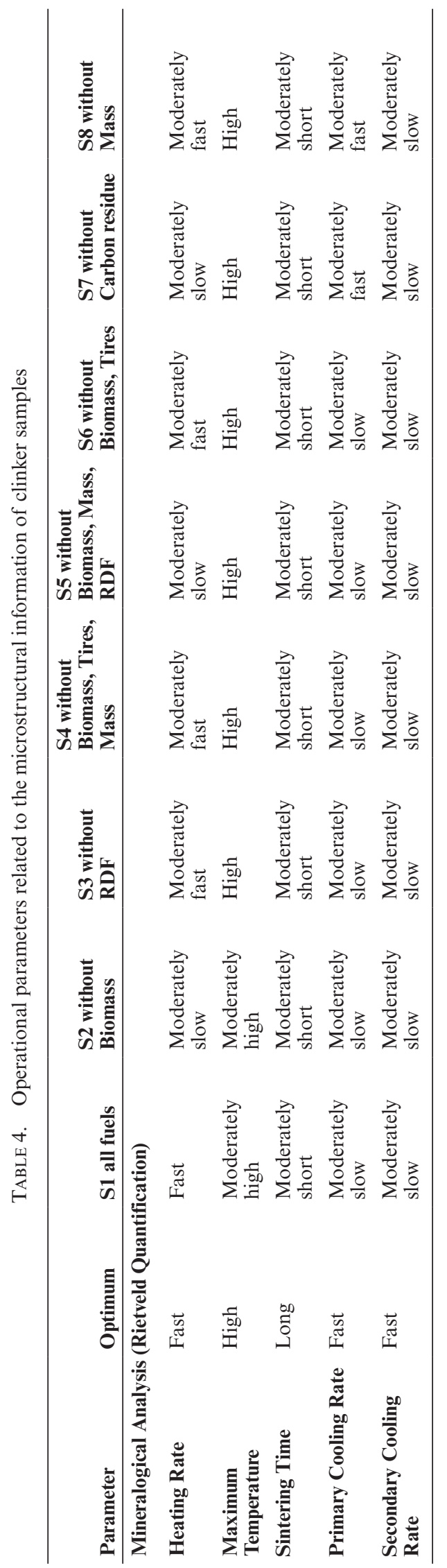



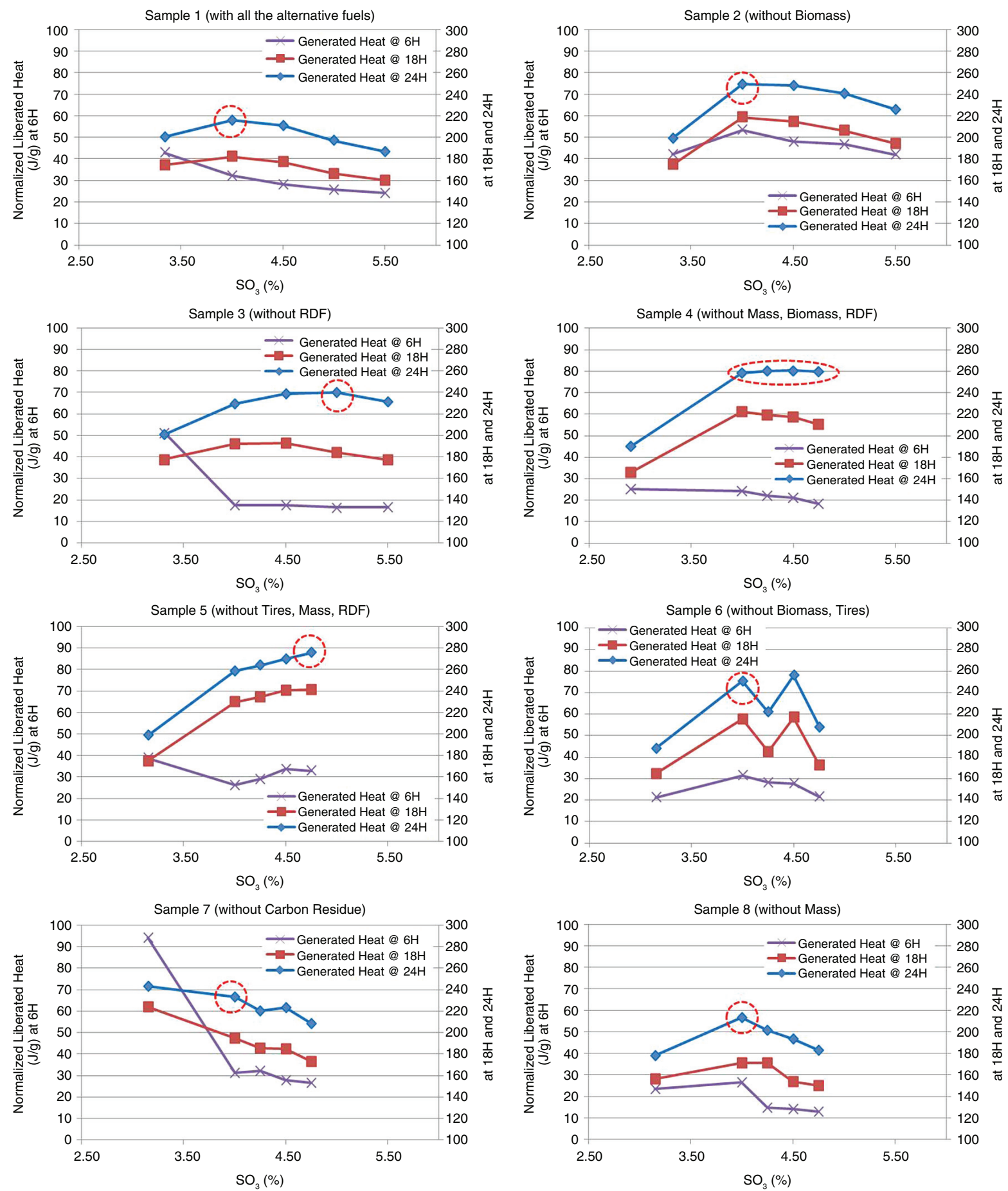

Figure 1. Isothermal Calorimetry at $23^{\circ} \mathrm{C}$ of original clinker samples with different $\mathrm{SO}_{3}$ levels (circles indicates the selected $\mathrm{SO}_{3}$ as the optimum for each case).

(S1), S2, S6, S7 and S8 and (b) $4.75 \%$ for S3 and S5. In particular, it is highlighted that S4 was not that sensitive to sulfate variation in the isothermal calorimetry test at 24 hours as shown in the graphic, it was not registered a significant change in the generated heat with different sulfate levels.

\subsubsection{Isothermal Calorimetry with cement admixture}

In cement production some chemical admixtures could be used during the grinding process to improve the hydration reaction of cement (14). The clinker composition and $\mathrm{SO}_{3}$ level of the cement 
could vary the interaction of the final formulation with the use of chemical admixtures. To clarify the effect of sulfate content isothermal calorimetry analysis was performed with two $\mathrm{SO}_{3}$ levels, $4.25 \%$ and $4.75 \%$, including $0.03 \%$ of a cement admixture with TEA as its main component.

The effect of TEA in the cement hydration is an acceleration of the calcium aluminates interaction with water (15). The later explains that with low $\mathrm{SO}_{3}$ content in the cement $(4.25 \%)$ and with the cement admixture incorporation, calorimetric curves experienced a change in its form. The sulfate depletion peak was shifted to the left with the use of TEA as admixture, confirming its accelerating effect over the hydration process and promoting the consumption of sulfate ions (Figure 2). In general, and as expected, a different profile was registered with high $\mathrm{SO}_{3}$ content in the cement $(4.75 \%)$, as seen in Figure 3, when calcium ions were more available in the system and the impact in the curve of the sulfate depletion was not that significant even though the acceleration of the aluminates was promoted even more by TEA addition.

Clinkers that showed more change with the use of the cement admixture were S3, S4, S6 and S8, where the height of the silicates peak (first peak) and the sulfate depletion peak (second peak) were almost the same. That change is related to an increase in the $\mathrm{C} 3 \mathrm{~A}$ content as in $\mathrm{S} 3$ and $\mathrm{S} 4$ and with the increase in the alite reactivity in S6 and S8, due to its change to a smaller crystal structure that promotes a higher rate of calcium ions consumption during its hydration. The shift in the hydration reaction was corrected in all the cases with more available calcium sulfate in the system, with high $\mathrm{SO}_{3}$ value.

\subsubsection{Isothermal Calorimetry with ready-mix admixture}

Ready-mix admixtures are used to modify the performance of the concrete during its hydration to facilitate the placing process, the main type of them, and the one selected for this study, is an ASTM-C-494 Type-D admixture (water reducer and retarder). The admixture was added at $8 \mathrm{ml} /$ $\mathrm{kg}$ cement, as an average of the actual industrial dosage with this type of admixture in the Mexican concrete market. The admixture was added to the mixing water according to the industrial practices, and maintaining the same water/cement ratio as in all the other isothermal calorimetric curves presented in this study ( 0.5 ratio).

As expected, due to the chemical nature of the admixture, with the use of water reducer a delay was registered in the time of the appearance of the maximum heat peak. The calorimetric analysis was performed with $4.25 \%$ of $\mathrm{SO}_{3}$, shown in Figure 4, and with $4.75 \%$ in Figure 5. With the use of readymix admixture, the reference cement presented 20 hours of delay in the maximum peak with the use of water reducer with no identified changes in the hydration profile, indicating low affectation of chemical agents to the ionic balance during the silicates and aluminates reaction. In contrast, all the modified clinkers presented higher retardation effect with ready-mix admixture, between 23 to 32 hours of delay, from 3 to 13 extra hours of effect, regarding calcium availability. As stated by Tuthill (7) the incorporation of a lignin based admixture affects the calcium balance during the hydration and impacts even the silicates reaction, causing a significant delay in its hydration due to a lack of calcium required to reach the supersaturated calcium solution at the silicates pores, what triggers its hydration. Extra calcium was consumed during the accelerated aluminates reaction, causing that the sulfate depletion peak was anticipated. Cements with $4.25 \%$ of $\mathrm{SO}_{3}$ that presented the most different performance with the water reducer were S3, S4, S6 and S8. They even end the dormant period with a non-well defined curve, indicating that the sulfate depletion peak shifted toward early ages. The interesting finding was the change registered in their curves when additional $\mathrm{SO}_{3}$ was added (up to $4.75 \%$ ), the sulfate depletion peak was displaced to the right, revealing the need of additional sulfate in the cements to promote its complete hydration process. This behavior is related to the highest Microscopy Score of S3, S4, S6 and S8, with a wellformed and more reactive alite and an increase in the $\mathrm{C}_{3} \mathrm{~A}$ identified by XRD for S3 and S4, which consumes sulfates in a prompt rate. S5 and S7 showed a minor change in its profile with the water reducer use, and a 2-3 hours higher delay in the maximum peak age. That is explained because, even though S5 and S7 changed to a more reactive alite, its aluminate content does not increased, so the sulfate consumption was not affected with the admixture, and just a displacement of all the curved was recorded, but not a particular modification of the sulfate depletion peak in the hydration profile.

In general, with a higher $\mathrm{SO}_{3}$ content all the modified clinker samples reported a minor retardation effect, moving the average from 23-32 hours for the maximum peak appearance with $4.25 \% \mathrm{SO}_{3}$ to 20-26 hours of delay with $4.75 \% \mathrm{SO}_{3}$, confirming the need of a higher sulfate level for the modified clinkers to obtain a smoother profile with water reducer due to the change in the equilibrium of the ions promoted by a chemical accelerator that interacts with $\mathrm{C}_{3} \mathrm{~A}$ and $\mathrm{C}_{3} \mathrm{~S}$ during its hydration. The reference remained with an equivalent thermal hydration profile regardless the sulfate content in the cement.

As expected, opposite from what was seen with TEA-based cement admixtures, with LS-based ready-mix admixtures a retardation effect is 

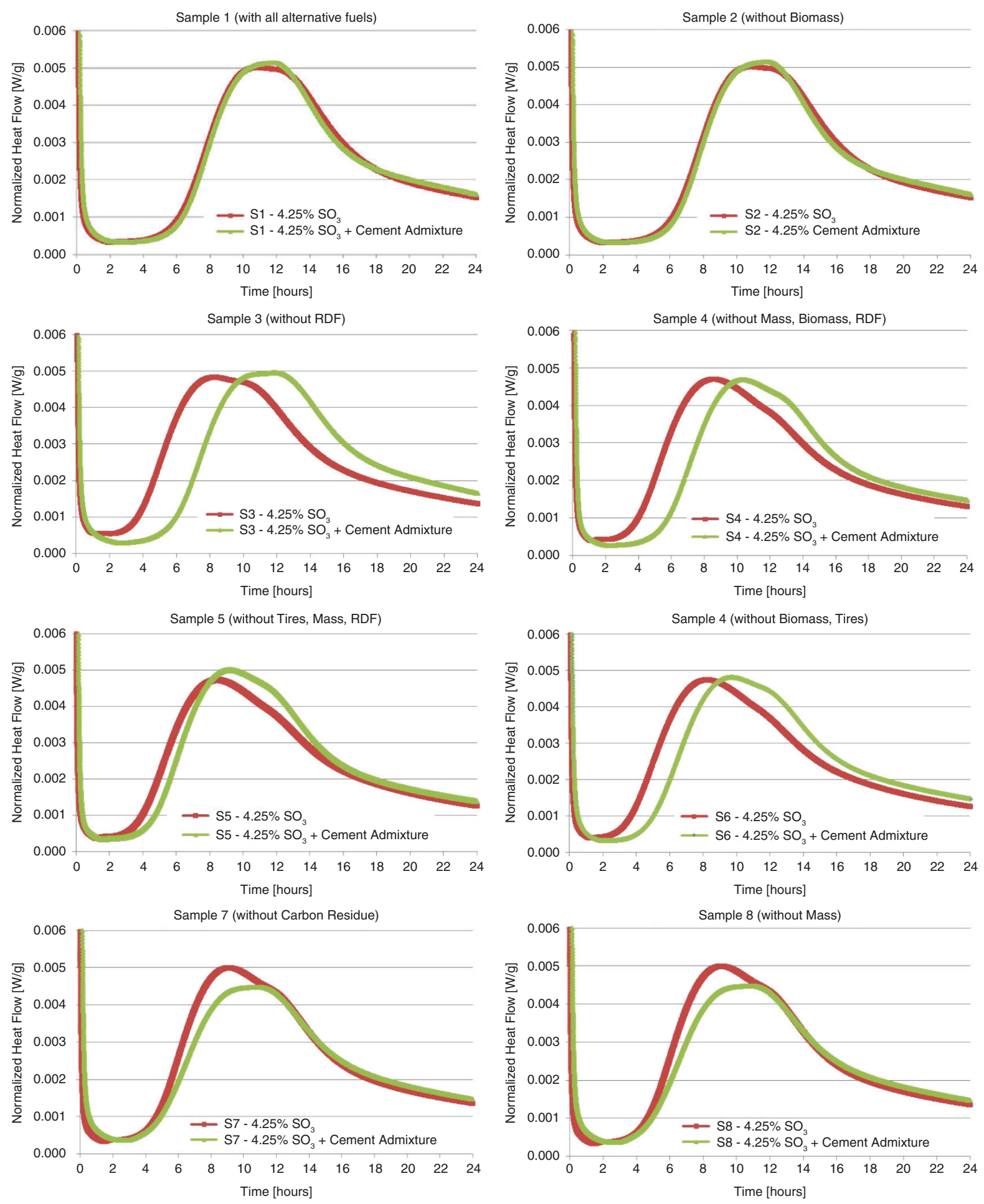

FIGURE 2. Isothermal Calorimetry with $0.03 \%$ of cement admixture with $\mathrm{S} 1-\mathrm{S} 8$ cements prepared with $4.25 \%$ of $\mathrm{SO}_{3}$.

promoted. The retardation effect is caused by a chemical reaction between lignosulfonate particles and dry cement particles forming a physical coat over anhydrous particles that prevents further contact with water, and a variation in the sulfate consumption due to the change in the calcium ions balance in the media, accelerating it by the aluminate reaction and finally affecting the silicate hydration. Increased efficiency of the admixture could be related to the surface and reactivity of the particles 

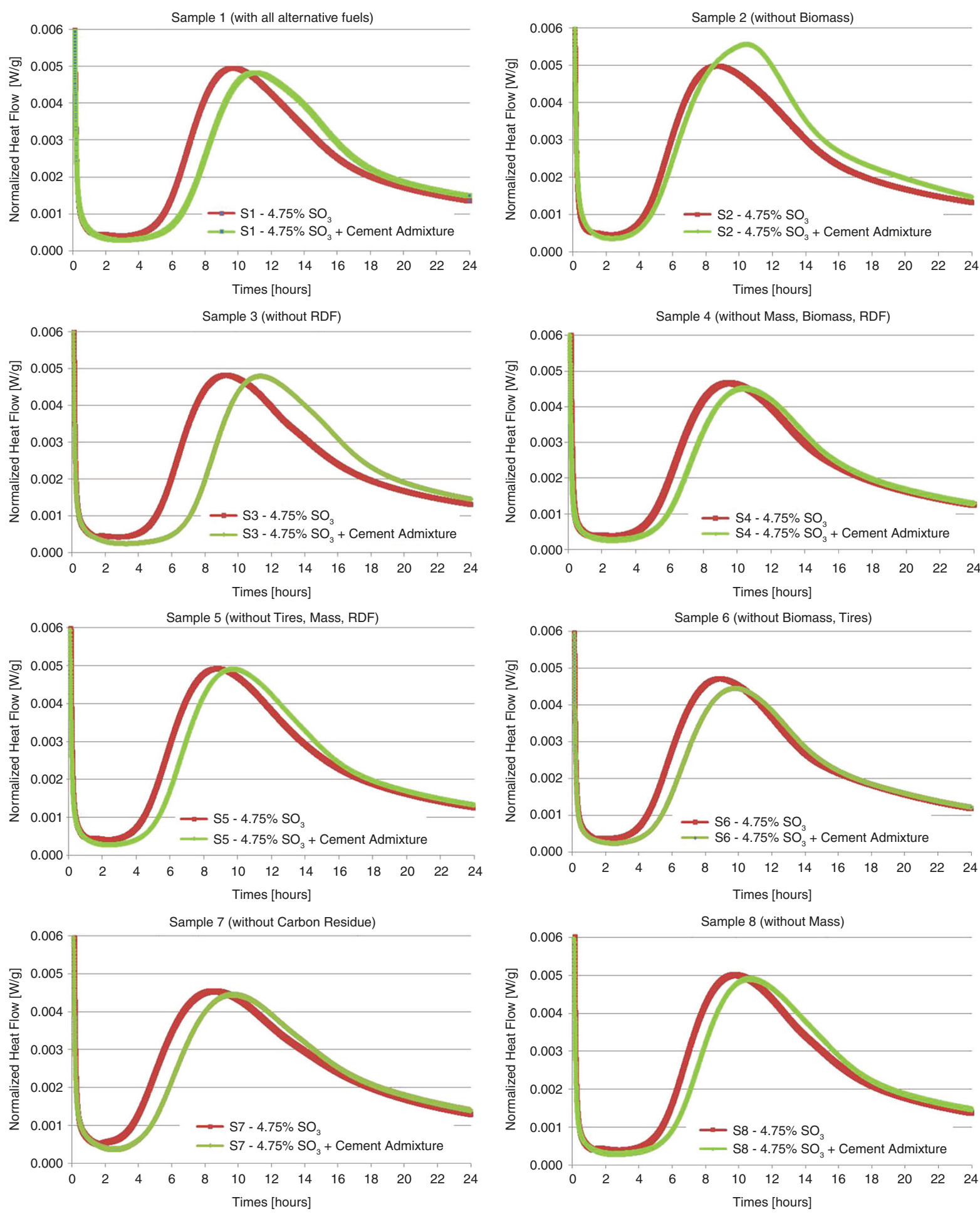

FIgURE 3. Isothermal Calorimetry with $0.03 \%$ of cement admixture with $\mathrm{S} 1-\mathrm{S} 8$ cements prepared with $4.75 \%$ of $\mathrm{SO}_{3}$.

with the removal of alternative fuels. This behavior indicates the need of an adjustment in the retarder dosage, considering the reactivity of the final clinker particles due to its aluminates and silicates proportion and crystalline structure.

\subsection{Compressive Strength}

The physical performance of the cements was determined using mortar compressive strength in 2 in. cubes. As indicated for Ordinary Portland Cement 

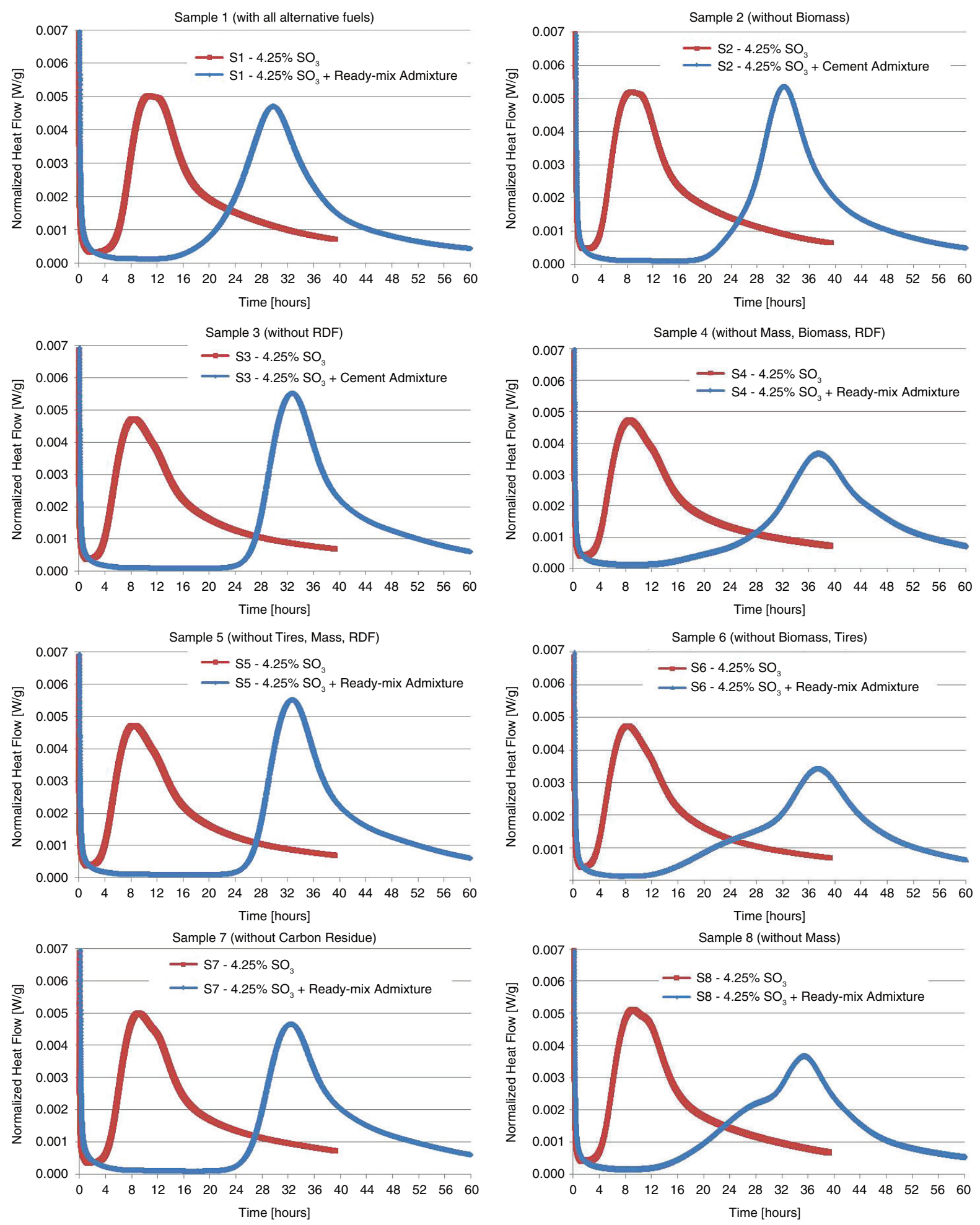

Figure 4. Isothermal Calorimetry with $0.03 \%$ of ready-mix admixture with $\mathrm{S} 1-\mathrm{S} 8$ cements prepared with $4.25 \%$ of $\mathrm{SO}_{3}$.

(OPC) the water/cement ratio remained constant as stated in the American norm ASTM-C-109 and Mexican norm NMX-C-414-ONNCCE, at 0.485 in all the cases. The results are shown in Figure 5 and in Figure 6. It is important to highlight that the physical testing of the cements did not include the use of cement or ready-mix admixture.

As identified in the calorimetric study, reference cement did not show a significant change in the early compressive strength with a variation in the 

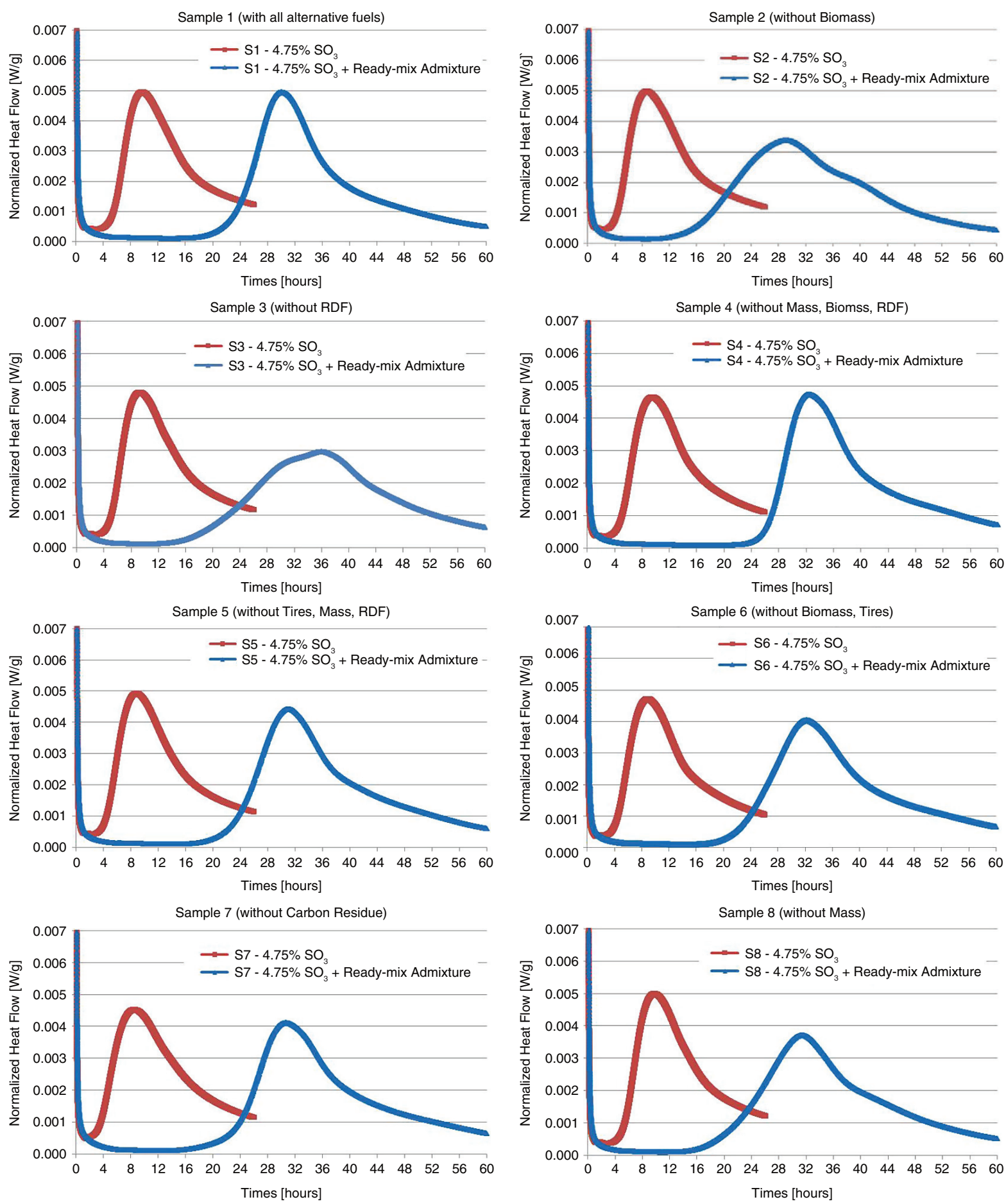

Figure 5. Isothermal Calorimetry with $0.03 \%$ of ready-mix admixture with $\mathrm{S} 1-\mathrm{S} 8$ cements prepared with $4.25 \%$ of $\mathrm{SO}_{3}$.

$\mathrm{SO}_{3}$ content, even though the high $\mathrm{SO}_{3}$ promoted the highest 28-days compressive strength. S2 and S3 had a similar behavior to the reference, being the least modified clinkers from the series without alternative fuels. And, in contrast, S4, S5, S6, S7 and S8 presented higher 1-day strength with the low sulfate content, without the use of any admixture.
The best performance with $4.25 \%$ of $\mathrm{SO}_{3}$ series was registered with $\mathrm{S} 4, \mathrm{~S} 5$ and $\mathrm{S} 8$, with around $18 \%$ - $21 \%$ of increase in 28-days compressive strength with $44-45 \mathrm{MPa}$ as an average compared to 37.5 $\mathrm{MPa}$ for the reference, S1. An improvement of the compressive strength was registered not only at 28-days but also in previous ages (1, 3 and 7-days). 
On the other hand, the single elimination of biomass and RDF, in S2 and S3, did not change significantly the compressive strength compared to the reference in the physical evaluation, nor any other clinker characterization parameter without the use of admixtures. With the increase in cement $\mathrm{SO}_{3}$ to $4.75 \%$ compressive strength at 28 -days was equivalent between all the samples. However, early compressive strength at 1-day decreased in the modified clinkers between $4 \%$ and $25 \%$ from the value of the reference (S1), as shown in Figure 6, indicating that the high $\mathrm{SO}_{3}$ level was not the optimum for its hydration when any accelerating agent was added, as TEA-based cement admixture or LS-based readymix admixture.

As determined by isothermal calorimetry, the optimum $\mathrm{SO}_{3}$ varies among the clinker samples. The reference, with all the alternative fuels, requires $4.75 \%$ of $\mathrm{SO}_{3}$ to improve its physical development at 28-days, even though it was not registered a beneficial impact at 1-day with the sulfate content variation, the compressive strength in early ages remained the same with the high and low sulfate level. On the other hand, almost all the modified clinkers were more sensitive in the early strength to the sulfate content, with the increase in the cement $\mathrm{SO}_{3}$ the results of 1-day were lowered, as the hydration reaction was delayed. The optimum $\mathrm{SO}_{3}$ considering 1-day and 28-days compressive strength for the reference was $4.25 \%$, in contrast to the $4.75 \%$ required for S4, S5 and S8 (Figure 7).

The cement producers have to meet physical performance specifications that guide their cement formulations, considering the type and reactivity of their produced clinker. Complementarily, the target for compressive strength of the cements is defined by the market demands and projects, cement producers should adjust its process to deliver the expected performance. Depending in the technology used for the clinker production in each plant its chemical and physical parameters could be changed, what impacts the formula used for the cement production. In the case of the alternative fuels is important to highlight that the general balance of its effect should consider not only the nature of the alternative fuels but also the technology used for its incorporation in the rotary kiln burners, to guarantee and facilitate its ignition.

Considering the obtained results, the alternative fuel that is most related to clinker reactivity in this study is the mass, as it was removed individually in S8 or in combination of other fuels in S4 and S5. With those clinkers compressive strength increased $20 \%$ respect the reference, and several parameters were changed in the clinker reactivity (the amount of $\mathrm{C}_{3} \mathrm{~A}$ and $\mathrm{C}_{4} \mathrm{AF}$ ) and the interaction profile in the isothermal calorimetry by itself and with cement and ready-mix admixtures. The improvement in the

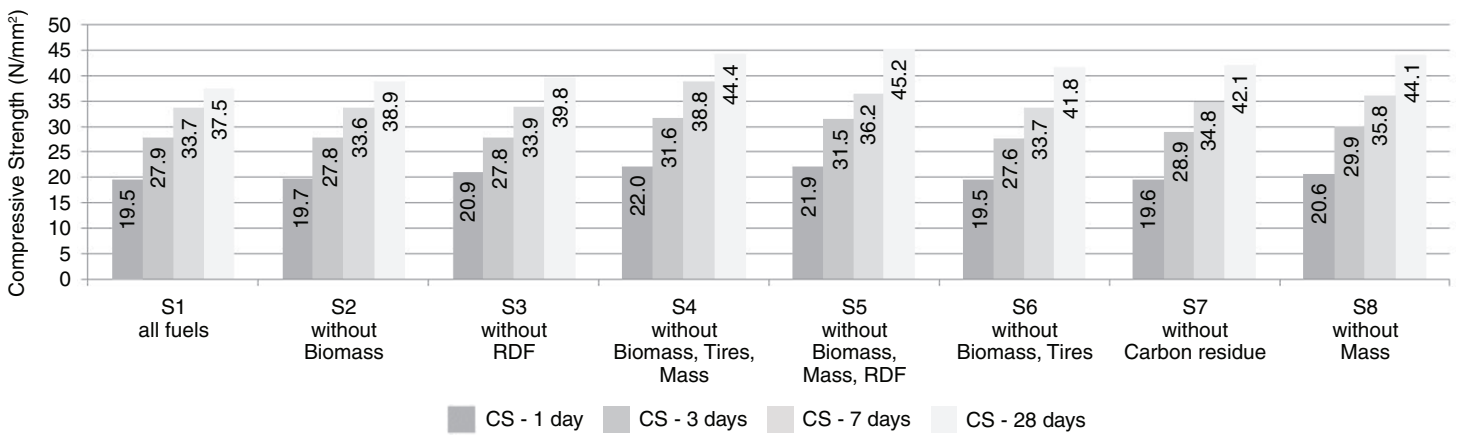

FIGURE 6. Mortar compressive strength of cements with $4.25 \%$ of $\mathrm{SO}_{3}$.

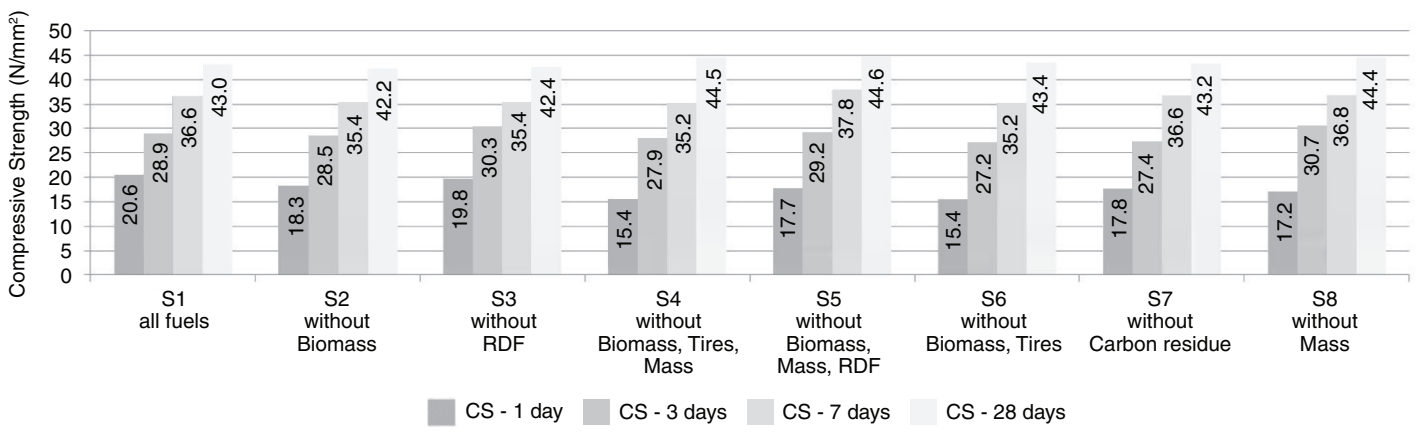

FIgURE 7. Mortar compressive strength of cements with $4.75 \%$ of $\mathrm{SO}_{3}$. 
compressive strength could be translated in around $3-4 \%$ of clinker content that should be adjusted to maintain the compressive strength of the final formulation of the cement, representing potentially an increase in the cost.

\section{CONCLUSIONS}

Analytical techniques indicated some differences between the clinker samples after replacing the alternative fuels; some of them having enough impact by itself to affect the physical behavior of the final formulated cement, which was verified with the isothermal calorimetry and compressive strength evaluations.

- X-ray diffraction (XRD) spectroscopy analysis showed slight changes in the structure of tricalcium silicate (alite- $\mathrm{C}_{3} \mathrm{~S}$ ) and the amount of tricalcium aluminate $\left(\mathrm{C}_{3} \mathrm{~A}\right)$ phases of several clinkers, phases that are responsible for the early hydration and strength. Mainly S7 with Carbon Residue and in S4, S5 and S6, with the removal of 2 or 3 alternative fuels was identified the presence of Mumme alite in combination with the other structures, decreasing the overall crystal size of the phase and increasing its reactivity.

- The hydration profile, specifically the sulfate depletion peak, obtained with isothermal calorimetry showed a change in the behavior of the modified clinkers with low $\mathrm{SO}_{3}$ content and the use of chemical admixtures (cement and readymix), which suggests for future research a need of an adjustment in the admixture dosage to reach the same benefit as in the clinker reference. The variations were minimized in that samples with the increase in the sulfate level of the cement $(4.75 \%)$.

- With the incorporation of the ready-mix admixture (ASTM-C-494 Type-D water reducer and retarder) the most affected isothermal calorimetry were S4, S6 and S8, samples with identified more $\mathrm{C}_{4} \mathrm{AF}$ and less $\mathrm{C}_{3} \mathrm{~A}$ in XRD analysis.

- The compressive strength of the clinkers with more than two alternative fuels removed decreased with the high sulfate content in the cement, in contrast with the reference, S2 and S3, registered as the least modified clinkers.

- The samples that showed the most significant changes in its alite polymorph conformation, its interaction with the LS-based ready-mix admixture and its response in the compressive strength with the change in $\mathrm{SO}_{3}$ were $\mathrm{S} 4, \mathrm{~S} 5, \mathrm{~S} 6$ and $\mathrm{S} 8$, where several alternative fuels were removed.

- The reference (S1) significantly improved its compressive strength with the increase in the sulfate content without changing the behavior at early ages as the rest of the clinker samples.
- Based in the results of the study, is indicated that the use of the alternative fuels has an effect over the clinker reactivity, and depending in the nature of the material is the magnitude of its impact. One of the alternative fuels related to the main changes in all the analytical techniques considered was the mass, present in S4, $\mathrm{S} 5$ and $\mathrm{S} 8$. Special attention should be paid to the changes in the produced clinker when a new alternative fuel is incorporated in the production process.

\section{REFERENCES}

1. Edenhofer, O. IPCC. (2014) Climate Change 2014: Mitigation of Climate Change. Contribution of Working Group III to the Fifth Assessment Report of the Intergovernmental Panel on Climate Change. http://www. globalchange.umd.edu/iamc_data/iamc2014/Edenhofer_ IAMC_17November.pdf

2. Cembureau. (1999) Environmental Benefits of Using Alternative Fuels in Cement Production: A Life-Cycle Approach. The European Cement Association.

3. G.H. Brundtland. (1987) Report of the World Commission on Environment and Development. United Nations General Assembly Oslo.

4. Trezza, M.; Scian, A. (2009) Estructura y Propiedades de Clinkers de Cemento Portland obtenidos con Combustibles Residuales. Revista de la Construcción, 8, 4-12.

5. Aldieb, M.; Ibrahim, H.G. (2010) Variation of Feed Chemical Composition and its effect on Clinker Formation Simulation Process. Proceeding of the World Congress on Engineering and Computer Science, San Francisco, 2.

6. Alemayehu, F.; Sahu, O. (2013) Minimization of variation in clinker quality. Adv. Materials, 2, 23-28. http://dx.doi. org/10.11648/j.am.20130202.12

7. Tuthill, L.H.; Adams, R.F.; Bailey, S.N.; Smith, R.W. (1961) A Case of Abnormally Slow Hardening Concrete for Tunnel Lining. ACI Journal, Proceedings 57 [3], 1091-1109.

8. Khalil, S.M.; Ward, M.A. (1978) Influence of $\mathrm{SO}_{3}$ and $\mathrm{C}_{3} \mathrm{~A}$ on the Early Reaction Rates of Portland Cement in the Presence of Calcium Lignosulfonate, American Ceramic Society Bulletin, 57 [ 12], 1116-1122.

9. NMX-C-059-ONNCCE, Norma Mexicana. (2014) Determinación del tiempo de fraguado de cementantes hidráulicos, Organismo Nacional de Normalización y Certificación de la Construcción y la Edificación, México.

10. NMX-C-061-ONNCCE, Norma Mexicana. (2014) Determinación de la resistencia a la compresión de cementantes hidráulicos, Organismo Nacional de Normalización y Certificación de la Construcción y la Edificación, México.

11. NMX-C-144-ONNCCE, Norma Mexicana. (2010) Determinación de la fluidez de morteros, Organismo Nacional de Normalización y Certificación de la Construcción y la Edificación, México.

12. Lerch, W. (1946) The influence of gypsum on the hydration and properties of Portland cement pastes. American Society of Testing Materials Procc., 46, 1252-1297.

13. Tsamatsoulis, D.; Nikolakakos, N. (2012) Investigation of Some Basic Parameters Affecting the Optimum Sulfates Content of Cement. Halyps Building Materials S.A., Italcementi Group 17 th Klm Nat. Rd. Athens - Korinth GREECE. ISBN: 978-1-61804-108-1.

14. Katsioti, M.; Tsakiridis, P.E.; Giannatos, P.; Tsibouki, Z.; Marinos, J. (2009) Characterization of various cement grinding aids and their impact on grindability and cement performance. Construc. Build. Mat., 23, 1954-1959. http:// dx.doi.org/10.1016/j.conbuildmat.2008.09.003

15. Ramachandran, V.S.; Lowery, M.S. (1992) Conduction Calorimetric Investigation of the Effect of Retarders on the Hydration of Portland Cement. Thermochim. Acta, 195, 373-387. http://dx.doi.org/10.1016/0040-6031(92)80081-7 